Gut, 1985, 26, 400-405

\title{
Topical administration of 5-aminosalicylic acid enemas in patients with ulcerative colitis. Studies on rectal absorption and excretion
}

\author{
M CAMPIERI, G A LANFRANCHI, S BOSCHI, C BRIGNOLA, G BAZZOCCHI, \\ P GIONCHETTI, M R MINGUZZI, A BELLUZZI, AND G LABÒ \\ From the Istituto di Clinica Medica e Gastroenterologia, Cattedra di Farmacologia Clinica, Policlinico $S$ \\ Orsola Università di Bologna, Bologna, Italy
}

SUMMARY 5-aminosalicylic acid (5-ASA) is a new treatment for patients suffering from ulcerative colitis but only limited information is available about its rectal absorption. We therefore studied seven patients with ulcerative colitis in remission, and five with active disease to determine acetylated and free 5-ASA plasma concentrations and urinary acetyl 5-ASA after the administration of three different types of enemas: $(2 \mathrm{~g} \mathrm{5-ASA} / 100 \mathrm{ml}, 4 \mathrm{~g} / 100 \mathrm{ml}$, and $200 \mathrm{ml})$. In patients in remission urinary acetyl 5-ASA excretion was dose and volume dependent $(\mathrm{p}<0 \cdot 01$; $\mathrm{p}<0.05$ ) but this correlation was absent in active disease. Because aminosalicylates are usually eliminated through the kidney, these low values (10\% in active disease and $19 \%$ in those in remission) suggest that the beneficial action may be local. Urinary recovery was significantly lower in patients with active disease $(p<0 \cdot 01 ; p<0 \cdot 02)$. No accumulation of 5-ASA was found in plasma after repeated daily administration.

Topical use of steroid derivatives ${ }^{1-3}$ provides local treatment for patients suffering from mild or moderate ${ }^{4}$ ulcerative colitis. There are promising reports about prednisolone metasulphobenzoate and beclomethasone dipropionate which are poorly absorbed ${ }^{5}{ }^{6}$ but a significant amount of prednisolone 21-phosphate is absorbed from the rectum when given as a retention enema, and it is still a matter of dispute whether its beneficial action is because of local, or systemic activity. ${ }^{78}$

More recently a new approach has been topical treatment with sulphasalazine ${ }^{910}$ or of its active constituent: 5-aminosalicylic acid (5-ASA). ${ }^{11-13}$ Administration of 5-ASA as high dosage enema was more effective than the $100 \mathrm{mg}$ hydrocortisone enemas in present use. ${ }^{14}$ Encouraging results have also been reported using other similar compounds such as sodium azodisalicylate ${ }^{15}$ salicylazobenzoic acid $^{16}$ and, more recently 4-aminosalicylic acid. ${ }^{17}$ There is little doubt 5-ASA of clinical efficacy but information available about its rectal absorption when given as suppositories ${ }^{12} 18$ is limited. This

Address for correspondence: Dr Massimo Campieri, 1 Clinica Medica Policlinico S Orsola Via Massarenti 9, 40138 Bologna, Italy.

Received for publication 30 March 1984 study was performed to measure peak plasma levels and urinary excretion of 5-ASA after rectal administration, as enemas.

\section{Methods}

PATIENTS

All the patients admitted to this investigation volunteered to take part in it after full explanation. Three different experiments were done.

\section{EXPERIMENT 1}

A single dose enema was administered to seven patients with ulcerative colitis in remission to determine the degree of absorption in relation to the volume and concentration. The patients were documented clinically, sigmoidoscopically, and histologically ${ }^{4}$ and were asked to retain an enema containing 4 g 5-ASA (Merck, Darmstadt, West Germany; product N $82009596 \%$ pure) suspended in $100 \mathrm{ml}$ water, for as long as possible. All patients retained the enema for up to 10 hours. Heparinised blood samples were taken immediately before administration, then every hour for at least eight hours consecutively and 24, 48 and 72 hours after administration of the enema. Two more blood 
samples were obtained at the ninth and 10th hour in five of the seven patients. Twenty four hour urine collections were made during the 72 hours after dosing. The study was repeated after a seven day interval with $2 \mathrm{~g}$ 5-ASA suspended in $100 \mathrm{ml}$ water and a third experiment was done after a similar interval with $4 \mathrm{~g}$ in $200 \mathrm{ml}$.

The enemas were prepared by the hospital pharmacists as a stock solution with only minor changes from published details. ${ }^{14}$ Before administering the enema the active agent was added. With $4 \mathrm{~g}$ 5-ASA the final $\mathrm{pH}$ of the suspension was 5.5-5.8; with $2 \mathrm{~g} \mathrm{pH}$ was $6 \cdot 1-6 \cdot 3$. The osmolality of the enema 5-ASA excluded was ${ }^{19} 390 \mathrm{mosm} / \mathrm{l}$. Using this method aimed to use 5-ASA, which is unstable as a fresh preparation administered as a suspended powder and not dissolved as an aqueous solution.

Blood samples were centrifuged and the plasma stored at $-20 \mathrm{C}$. Free 5-ASA and acetyl-5-ASA were measured fluorimetrically as described by Hansson. ${ }^{20}$ The same procedure was used for urine specimens. Some urine samples were also analysed by HPLC $^{18}$ in order to exclude quenching phenomena, but as the results were similar only the first method was used. Student's $t$ test for paired and unpaired data was used for statistical analyses.

\section{EXPERIMENT 2}

A single dose enema was given to patients with active left sided disease to determine the effect of active inflammation on the absorption of 5-ASA. The design was similar to study 1. A few modifications adopted were: the three treatments were given in a predetermined random order with a two-day interval between each study. The change in the protocol was for ethical reasons and was possible because 5-ASA was mainly eliminated within 24 hours. Five outpatients with mild to moderate relapses volunteered to take part in this study.

\section{EXPERIMENT 3}

Measurements of 5-ASA plasma concentrations were made during a prolonged period of treatment. As 5-ASA is generally given to patients with active disease for at least a 15 day or one month course 16 patients were asked to attend the outpatient clinic in the middle and at the end of the treatment, in order to verify whether daily enema administration might lead to an accumulation of 5-ASA in the blood: two had a proctitis, eight sigmoiditis, and in the other six the disease extended to the splenic flexure. Blood samples were collected in the afternoon - that is, at about 18 hours after the retention enema. None of the patients studied was taking oral sulphasalazine as maintenance treatment.
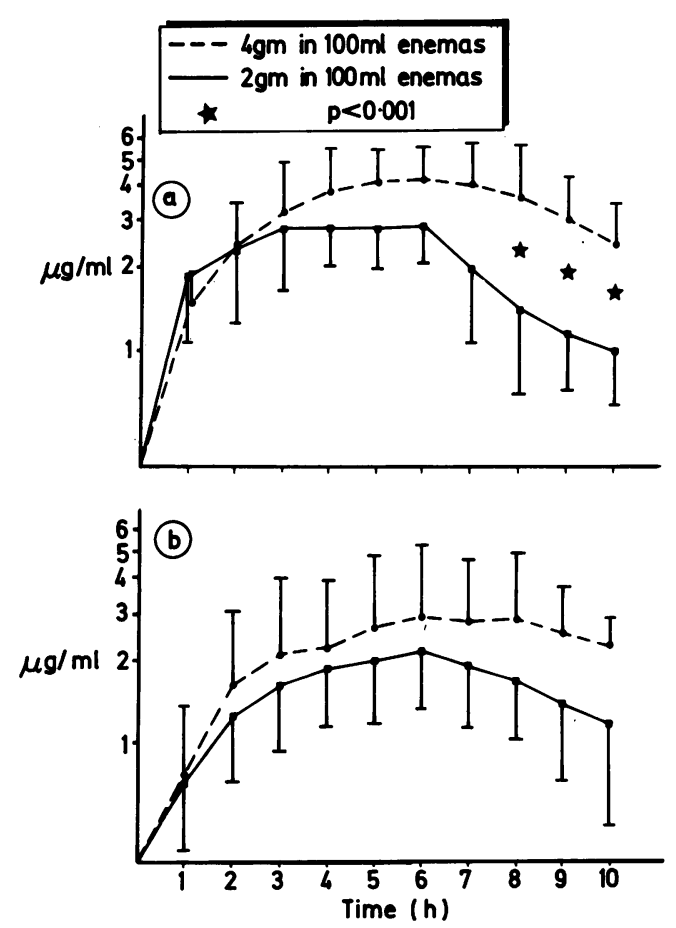

Fig. 1 Plasma concentrations of total 5-ASA (mean $\pm S D$ ) in 7 patients with $U C$ in remission $(a)$; and in 5 patients with active $U C(b)$.

\section{Results}

EXPERIMENT 1

Figure 1a shows that plasma concentrations of total 5-ASA vary with time after enemas containing 2 and $4 \mathrm{~g}$ 5-ASA suspended in $100 \mathrm{ml}$. The peak levels, which never exceed $7 \mu \mathrm{g} / \mathrm{ml}$ were reached within three to six hours. After eight, nine and 10 hours, the mean peak plasmatic values for $2 \mathrm{~g}$ in $100 \mathrm{ml}$ were significantly lower than for $4 \mathrm{~g}$ in $100 \mathrm{ml}(\mathrm{p}<0.001)$. After 24 hours only negligible levels (from 0 to $0 \cdot 1$ $\mu \mathrm{g} / \mathrm{ml}$ were recorded after all types of enemas and plasma 5-ASA was undetectable after 48 hours.

Most ( $>90 \%$ ) of 5-ASA detected in the urine (all in acetylated form) was excreted in the first 24 hours. The urinary values were dependent on the concentration of the enema, being significantly greater for $4 \mathrm{~g}$ than $2 \mathrm{~g}(\mathrm{p}<0.01)$ and were respectively $16 \%$ (range $13-21 \%$ ) and $17 \%$ (range $10-26 \%$ ) of the administered dose. When the volume was doubled, the urinary excretion was significantly increased $(p<0.05)$ (Table 1$)$.

EXPERIMENT 2

It can be seen in Figure $1 \mathrm{~b}$ that in patients with 
Table 1 Urinary recovery of acetyl-5-ASA (mg) excreted in urine in the first $24 \mathrm{~h}$ after dosing by patients in remission

\begin{tabular}{|c|c|c|c|c|c|c|c|}
\hline \multirow[b]{2}{*}{ Patients } & \multirow[b]{2}{*}{ Extent of disease } & \multicolumn{6}{|l|}{ Enemas } \\
\hline & & $\begin{array}{l}2 \mathrm{~g} \\
100 \mathrm{ml}\end{array}$ & $\begin{array}{l}\text { (time of } \\
\text { retention } h \text { ) }\end{array}$ & $\begin{array}{l}4 \mathrm{~g} \\
100 \mathrm{ml}\end{array}$ & $\begin{array}{l}\text { (time of } \\
\text { retention } h \text { ) }\end{array}$ & $\begin{array}{l}4 \mathrm{~g} \\
200 \mathrm{ml}\end{array}$ & $\begin{array}{l}\text { (time of } \\
\text { retention } h \text { ) }\end{array}$ \\
\hline 1 & Leftsided & 470 & $(12.05)$ & 685 & (11.45) & 964 & (11.30) \\
\hline 2 & Sigmoid & 201 & (10.15) & 878 & (10.55) & & \\
\hline 3 & Sigmoid & 216 & (11.00) & 665 & (10.15) & & \\
\hline 4 & Leftsided & 470 & (11.20) & 670 & (10.30) & 890 & (11.15) \\
\hline 5 & Leftsided & 235 & $(11.00)$ & 532 & (11.10) & 1506 & (12.10) \\
\hline 6 & Rectum & 532 & (12.10) & 820 & (12.00) & & \\
\hline 7 & Sigmoid & 530 & (11.10) & 547 & $(10.30)$ & 745 & $(11.10)$ \\
\hline Mean \pm SD & & $379 \pm 153 \cdot 7$ & & $89 \pm 123 \cdot 5$ & & $1026+332 \cdot 4$ & \\
\hline $\begin{array}{l}\text { Percentage } \\
\text { (range) }\end{array}$ & & $\begin{array}{c}17 \\
(10-26)\end{array}$ & & $\begin{array}{c}16 \\
(13-21)\end{array}$ & & $\begin{array}{c}25 \\
(18-37)\end{array}$ & \\
\hline
\end{tabular}

active disease the mean plasma concentrations were generally similar to those in experiment 1 . The mean percentage of urinary recovery of acetyl-5-ASA (Table 2) was dose and volume dependent, but no statistical difference was detected between the three treatments. Comparing the results of these treatment groups with the corresponding groups of the first experiment, the mean urinary acetyl-5-ASA was lower when the disease was active being statistically significant for $4 \mathrm{~g}$ in 100 and $200 \mathrm{ml}$ $(\mathrm{p}<0.01 ; \mathrm{p}<0 \cdot 02)$ (Fig 2).

\section{EXPERIMENT 3}

Practically no plasma accumulation of total 5-ASA was observed in 12 patients after 15 days treatment with $2 \mathrm{~g}$ or $4 \mathrm{~g}$ enemas. On day 16 the mean plasma value was $0.27 \mu \mathrm{g} / \mathrm{ml}$ (range $0-1.5$ ) and on day 17 $0 \cdot 18 \mu \mathrm{g} / \mathrm{ml}$ (range $0-0.90$ ). A similar result was also observed after one month's treatment in the other four patients with $2 \mathrm{~g}$ enemas only; on day 31 we found $0.45 \mu \mathrm{g} / \mathrm{ml}$ (range $0.2-0.7$ ); and on day 32 $0 \cdot 09$ (range $0 \cdot 01-0 \cdot 2$ ).

RATIO ACETYLATED/FREE 5-ASA\%

Figure 3 shows the mean plasma values of total, acetyl, and free 5-ASA detected in patients treated respectively with $2 \mathrm{~g} 5$-ASA in $100 \mathrm{ml}$ or $4 \mathrm{~g} 100 \mathrm{ml}$. Most of the 5-ASA was in acetylated form; comparison of areas under the curves shows that in patients taking $2 \mathrm{~g}$ or 5-ASA, the acetyl 5-ASA was $76 \pm 12 \%$ (SD) of total 5-ASA; for $4 \mathrm{~g}$ enema the values were of $82 \pm 11 \%(\mathrm{SD})$.

\section{Discussion}

This study shows that after rectal administration 5-ASA is absorbed to a variable extent; mean values of total 5-ASA peak plasma concentrations are

Table 2 Urinary recovery of acetyl-5-ASA (mg) excreted urines in the first 24 h after dosing by patients with active disease

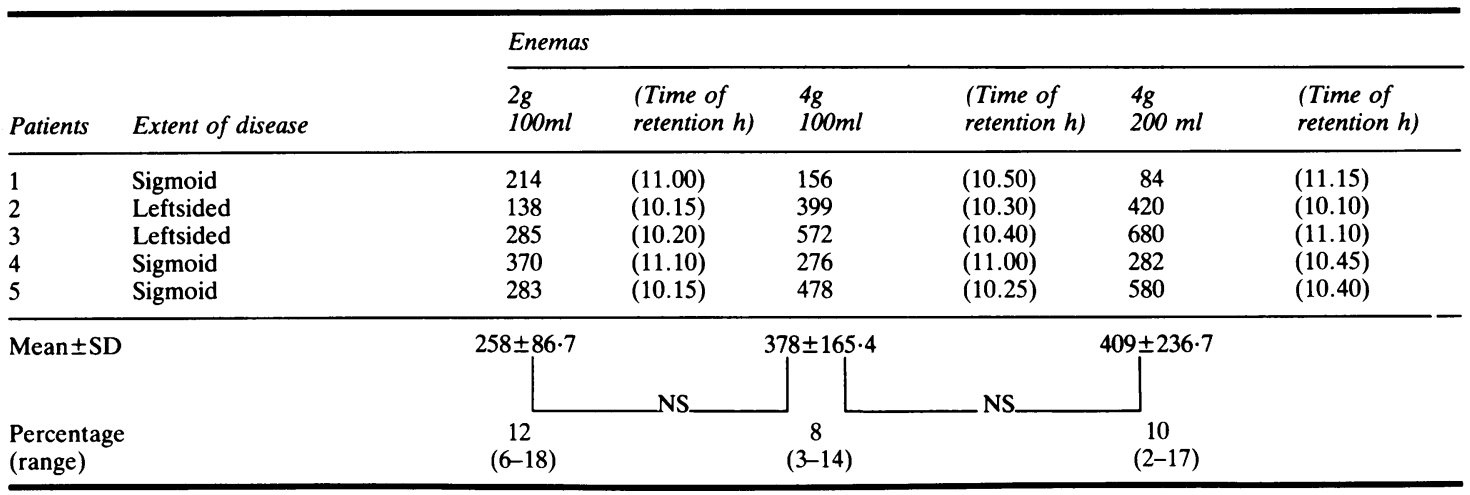




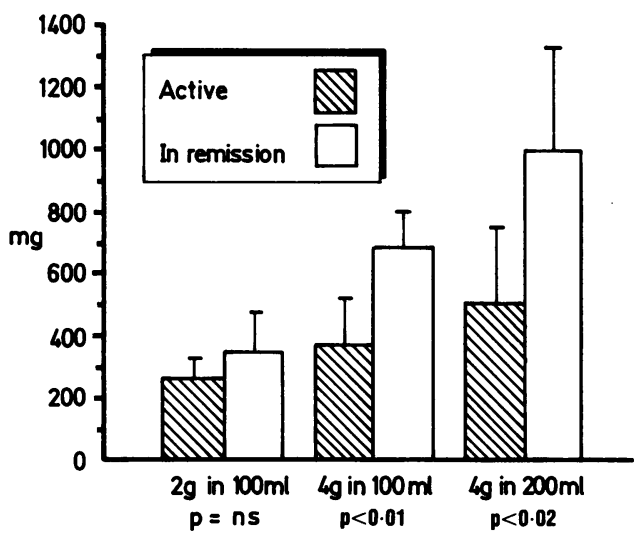

Fig. 2 Overall 24 hour urinary recovery of acetyl 5-ASA (mean $\pm S D)$.

greater than those reported after oral sulphasalazine administration 2122 and 5-ASA as a slow release preparation, ${ }^{25}$ but are lower than those reported after $4 \mathrm{~g}$ 4-ASA given orally for tuberculosis ${ }^{23}$ and negligible compared with the therapeutic range of salicylates. ${ }^{24}$ It has recently been reported that after
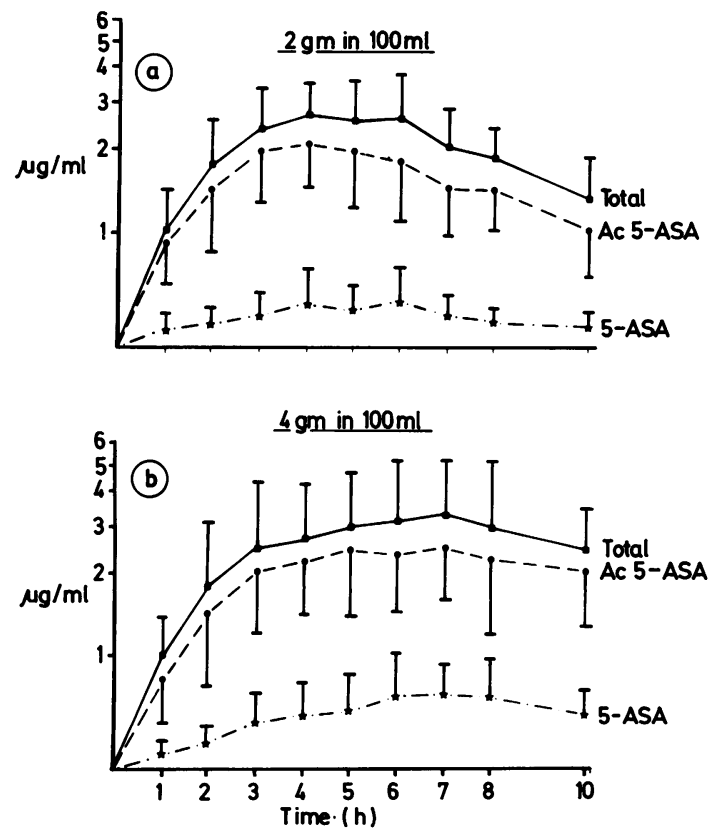

Fig. 3 Mean plasmatic concentrations ( $\pm S D$ ) of total, acetyl and free 5-ASA in 12 colitics with active or quiescent disease, receiving $2 \mathrm{~g} 5-A S A$ in $100 \mathrm{ml}$ enemas (a) and $4 \mathrm{~g}$ in 100 ml enemas $(b)$. sodiumazodisalicylate (ADS) was administered rectally ${ }^{28}$ very low plasma values were obtained for total 5-ASA and for ADS.

In a previous report using 5-ASA $1.5 \mathrm{~g}$ as suppositories Fischer et $a l^{18}$ reported plasma concentrations of total 5-ASA which were considerably lower than those recorded here. The reason for this discrepancy might be the different methods of treatment. Fischer et al used suppositories which might have acted only locally, while enemas which spread to the splenic flexure (unpublished observation), allowed greater surface for absorption of the drug.

The negligible levels of total 5-ASA recorded after 24 hours are probably due to immediate evacuation by most patients immediately after the end of the experiment with a rapid fall of plasma curve ( $T \frac{1}{2}$ about one hour). In Figure 4 are described the plasmatic values obtained in two patients who did not retain the enemas for the whole experiment. This may also account for the lack of plasma accumulation after prolonged treatment of up to one month (Experiment 3) which represents a safe feature of this therapeutic approach.

The urinary recovery of acetyl-5-ASA in the 24 hour urine was $19 \%$ (range 10-37\%) in patients with disease in remission, and $10 \%$ (range $2-18 \%$ ) in patients with active diseases. Considering that aminosalicylates are almost completely excreted through the kidneys, ${ }^{23}$ these low values might suggest that 5-ASA exerts its therapeutic benefit mainly through a local action.

On increasing the concentration of enemas the urinary recovery is proportionally higher; this also occurs when the volume is doubled because the retrograde spread of 5-ASA enemas is volumedependent (unpublished observations). The lower levels of urinary recovery found in patients with

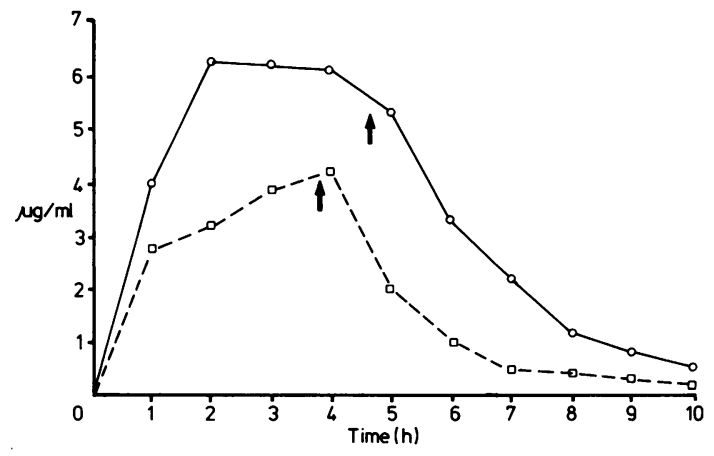

Fig. 4 Rapid fall of plasmatic total 5-ASA after evacuation (arrows). 
active disease $(4 \mathrm{~g} / 100 \mathrm{ml}$ and $200 \mathrm{ml})$ might only partially be explained by the period of retention of enemas; it is likely that the presence of blood and mucus, the severity of inflammatory process, and luminal $\mathrm{pH}$ might also have some determinant role. ${ }^{26} 27$

Another consideration is described in the data in Figure 3 where the mean values of total, acetyl, and free 5-ASA are reported. The first two values run in a parallel way independently of the concentration of the enemas. These similar percentages of acetylation in the different subjects for different dosages might suggest that the acetylation process does not take place in the liver as reported for sulphasalazine; in fact its most absorbed metabolite, sulphapyridine, is acetylated in the liver according to a genetically determined phenotype. ${ }^{29}$ Therefore, the similar percentage of acetylation might support the idea, already suggested ${ }^{30}$ that this process takes place in the colon.

5-ASA high dosage enemas, because of their clinical efficacy and mainly local therapeutic effects, can be considered a suitable form of topical treatment for ulcerative colitis. As aminosalicylates are mainly eliminated through the kidney it is essential that the renal function should be normal. Even if found normal, renal function tests should be done serially to exclude possible nephrotoxicity. ${ }^{31}$

The authors are indebted to Mr Rino Facchini for skilful technical assistance. We wish also to express our personal gratitude to Dr D P Jewell (Oxford) and Dr D E S Campbell, Pharmacia (Uppsala) for helpful suggestions and criticisms.

\section{References}

1 Truelove SC, Treatment of ulcerative colitis with local hydrocortisone hemisuccinate sodium. A report of a controlled therapeutic trial. $\mathrm{Br}$ Med J 1958; 2: 1267-72.

2 Matts SGF. Intrarectal treatment of one hundred cases of ulcerative colitis with prednisolone 21-phosphate enemata. Br Med J 1976; 1: 193-5.

3 Multicentre trial - Betamethasone 17 - valerate and prednisolone 21-phosphate retention enemata in proctocolitis. $\mathrm{Br}$ Med J 1971; 3: 84-6.

4 Truelove SC, Richards WCD. Biopsies studies in ulcerative colitis. $\mathrm{Br} \mathrm{Med} J$ 1956; 1: 1315-8.

5 Lee DAH, Taylor M, James WHT and Walker J. Rectally administered prednisolone. Possible evidence for a predominantly local action. Gut 1980; 21 : 215-8.

6 Kumana CR, Seaton T, Meghji M, Castelli M, Benson R, Sivakumakan T. Beclomethasone dipropionate enemas for treating inflammatory bowel disease without producing Cushing's syndrome or hypotalamic- pituatary adrenal suppression. Lancet $1982 ; 1: 579-83$.

7 Lee DAH, Taylor M, James WHT and Walker G. Plasma prednisolone levels and adrenocortical responsiveness after administration of prednisolone 21-phosphate as a retention enema. Gut 1979; 20: 349-55.

8 Powell-Tuck J, Lennard-Jones JE, May CS, Wilson CG and Paterson JW. Plasma prednisolone levels after administration of prednisolone 21-phosphate as a retention enemas in colitis. $\mathrm{Br}$ Med J 1976; 1: 193-5.

9 Fruhmorgen P, Demling L. On the efficacy of readymade-up commercially available Salicylazosulphapyridine in the treatment of proctitis, proctosigmoiditis and ulcerative colitis. Hepato-Gastroenterology 1980; 27: 473-6.

10 Palmer KR, Goepel JR, Holdsworth CD. Sulphasalazine retention enemas in ulcerative colitis: a double blind trial. Br Med J 1981; 1: 1571-3.

11 Azad Khan AK, Piris J, Truelove SC. An experiment to determine the active therapeutic moiety of sulphasalazine. Lancet 1977; 2: 892-5.

12 Van Hees PAM, Bakker JH, Van Tongeren JHM. Effect of sulphapyridine, 5-aminosalicylic acid and placebo in patients with idiopathic proctocolitis: a study to determine the active therapeutic moiety of sulphasalazine. Gut 1980; 21: 632-5.

13 Klotz U, Maier K, Fischer C, Heikel K. Therapeutic efficacy of sulphasalazine and its metabolites in patients with ulcerative colitis and Crohn's disease. N Engl J Med 1980; 303: 1499-502.

14 Campieri M, Lanfranchi GA, Bazzocchi G, Brignola C et al. Treatment of ulcerative colitis with high dosage 5-aminosalicylic acid enemas. Lancet 1981; 2: 270-1.

15 Jewell DP, Truelove SC. Disodium azodisalicylate in ulcerative colitis. Lancet 1981; 2: 1168.

16 Bartalsky A. Salicylazobenzoic acid in ulcerative colitis. Lancet 1981; 2: 1168.

17 Campieri M, Lanfranchi GA, Bertoni F, et al. A double-blind clinical trial to compare the effects of 4-aminosalicylic acid to 5-aminosalicylic acid in topical treatment of ulcerative colitis. Digestion 1984; 29: 204-8.

18 Fischer C, Maier K, Klotz U. Simplified high performance chromatographic method for 5aminosalicylic acid in plasma and urine. J Chromatogr 1981; 222: 498-503.

19 Raitano A, Campieri M, Mussi T et al. 5-aminosalicylic acid enemas. Lancet 1982; 1: 102.

20 Hansson KA. Determination of free and acetylated 5 -aminosalicylic acid in serum and urine after administration of salicylazosulphapyridine. Acta Phar Suec 1973; 10: 1953-5.

21 Schroeder H, Campbell DES. Absorption, metabolism and excretion of salicylazosulphapyridine in man. Clin Pharmacol Ther 1972; 13: 539-51.

22 Peppercorn MA, Goldman P. Distribution studies of salicylazosulphapyridine and its metabolites. Gastroenterology 1973; 64: 240-5.

23 Goodman AG, Gilman A. The pharmacological basis of therapeutics: aminosalicylic acid. Edinburgh: MacMillan, 1980: 209-1210.

24 Goodman AG, Gilman P. The pharmacological basis of 
therapeutics: the salicylates. Edinburgh: MacMillan, 1980: 668-689.

25 Rasmussen SN, Bondesen S, Hvidberg EF, Binder V, Halskov S, Flachjs H. 5-aminosalicylic acid in a slow-release preparation: bioavailability, plasma level, and excretion in humans. Gastroenterology 1982; 83: 1062.

26 Bechgaard E. Absorption of salicylic acid from the perfused human rectum. Acta Pharmacol Toxicol 1973; 33: $129-37$.

27 De Boer AG, Moolenaar F, De Leede IGJ, Breimer DD. Rectal drug administration: clinical pharmacokinetics considerations. Clinical Pharmacokinetics 1982; 7: 285-311.

28 Sandberg Gertzen H, Ryde M, Jarnerot G. Absorption and excretion of azodisal sodium and its metabolites in man after rectal administration of a single $2 \mathrm{~g}$ dose. Scand J Gastroenterol 1983; 18: 571-5.

29 Das KM, Eastwood MA, McManus JRA, Sircus W. Adverse reaction during salicylazosulphapyridine therapy and the relation with drug metabolism and acetylator phenotype. $N$ Engl J Med 1973; 289: 491-5.

30 Willoughby CP, Aronson JK, Agback H, Bodin NO, Truelove SC. Distribution and metabolism in healthy volunteers of disodium azodisalicylate, a potential therapeutic agent for ulcerative colitis. Gut 1982; 23: 1081-7.

31 Calder IC, Funder CC, Green CR, Ham KN, Tange JD. Nefrotoxic lesions from 5-aminosalicylic acid. $\mathrm{Br}$ Med J 1972; 1: 152-4. 